* Professor Adjunto da Faculdade de Direito do Recife, Mestre e Doutor pela UFPE, Pós-Doutor pela Faculdade de Direito da Universidade de LisboaFDUL. Bolsita da Capes. Email: silviorb@gmail.com

\section{A adequação da relação médico- paciente aos requisitos de validade do negócio jurídico: a relação médico-paciente como fenômeno jurídico}

\author{
The ADEQUaCy OF DOCTOR PATIENT THE \\ RELATIONSHIP TO THE REQUIREMENTS OF VALIDITY \\ OF THE LEGAL TRANSACTION: THE DOCTOR \\ PATIENT RELATIONSHIP AS LEGAL PHENOMENON
}

* Silvio Romero Beltrão

Resumo: O presente trabalho tem o caráter interdisciplinar e pretende analisar a adequação da relação médico-paciente aos requisitos de validade do negócio jurídico. A relação médicopaciente necessita de uma visão completa quanto aos elementos e requisitos que constituem a sua validade na ordem jurídica. Como ponto de partida analisa a relação médico-paciente como fato jurídico, para em seguida verificar os requisitos de validade do negócio jurídico médico-paciente, agente capaz, objeto licito e forma prescrita em lei. Investiga a manifestação da vontade como principal elemento do negócio jurídico para definir ao final a importância do estudo da relação médico-paciente pelo Direito, com base na Teoria Geral do Direito Civil.

Palavras-chave: Relação médico-paciente; Negócio jurídico; Requisitos de validade; Interdisciplinar; Medicina e direito.

Abstract: This work is interdisciplinary and aims to examine the adequacy of the patient-physician relationship to the requirements of validity of legal business. The doctor-patient relationship needs a complete overview on the elements and requirements that constitute its validity in law. As a starting point analyzes the doctor-patient relationship as a legal fact, to then verify the validity requirements of the patient medical legal business, capable agent, object and lawful manner prescribed by law. Investigating the manifestation of the will as the main element of the legal transaction to define the end of the study the importance of the doctor-patient relationship by law, based on the General Theory of Civil Law.

Keywords: Doctor-patient relationship; Legal business; Validity requirements; Interdisciplinary; Medicine and law. 


\section{INTRODUÇÃO}

A relação médico-paciente não é um elemento estático da vida em sociedade. Para além da ideia de paciente como pessoa em busca de um tratamento para prover o seu bem estar físico e mental, e da ideia de médico como o profissional da medicina em quem repousam todas as expectativas do paciente, há a noção de relação jurídica a qual demonstra um caráter dinâmico nas ações praticadas pelas pessoas criando, modificando e extinguindo a realidade exterior. ${ }^{1}$

Dentro da noção de fenômeno jurídico os fatos envolvendo o médico e o paciente são acontecimentos que criam, modificam e extinguem relações jurídicas, ou seja, produzem efeitos jurídicos, que se revelam a partir da caracterização do fato relacionado ao tratamento e a cura do paciente.

A conduta da pessoa humana através de suas ações são fatos jurídicos que modificam a realidade em sua volta (ASCENSÃO, 1999, p. 8). Tipicamente, o fato jurídico prestação de serviços médicos pode criar para o paciente o direito de ser respeitado quanto à decisão relativa ao tratamento que quer se submeter; pode permitir ao médico que se recuse a realizar determinado procedimento terapêutico que seja contrário aos ditames de sua consciência; e pode impor ao médico responsabilidade civil pelos danos causados ao paciente por imperícia, imprudência ou negligência. O Direito, em seu sentido objetivo, regula através de suas normas jurídicas as relações entre as pessoas na sociedade. A relação entre médico e paciente não escapa da regulação do direito, pois, os acontecimentos e eventos envolvendo essas pessoas são regidos por regras jurídicas, produzindo efeitos no mundo jurídico. ${ }^{2}$

\footnotetext{
1 "Facto jurídico é todo facto (actuação ou simples ocorrência) da vida real (máxime da vida social) produtivo de efeitos jurídicos, ou - por outras palavras - todo o facto da vida real juridicamente relevante. Contrapõe-se ao facto simples, material ou neutro, que vem a ser todo o facto da vida real juridicamente indiferente, isto é, a que a ordem jurídica não liga quaisquer consequências. Assim: a cor dos olhos duma pessoa, a sua preferência por certa marca de cigarros ou por certo team de futebol, o facto de um indivíduo deixar em casa doutro o seu cartão de pêsames pelo falecimento de uma pessoa de família, de ir dar um passeio depois do jantar, etc. Tudo isto são factos da vida social ou real que, considerados em si mesmos, resultam completamente indiferentes ao direito. São portanto factos juridicamente irrelevantes, factos destituídos de eficácia jurídica, factos neutrais, sob o ponto de vista do direito - factos ajuridicos, em suma."(ANDRADE, 1974, p. 1).

2 Ementa: RESPONSABILIDADE CIVIL. MEDICAÇÃO EQUIVOCADA. DANO MORAL IN RE IPSA. QUANTUM. O fornecimento de remédio equivocado acarreta dano moral indenizável, não sendo necessária a prova acerca do prejuízo. As adversidades sofridas pelo autor, a aflição e o desequilíbrio em seu bem-estar, fugiram à normalidade e se constituíram em agressão à sua dignidade. Minoração do montante indenizatório considerando o equívoco da ré, o comportamento do demandante, as circunstâncias do caso concreto, além do caráter punitivo-compensatório da reparação. APELAÇÃO DA RÉ PARCIALMENTE PROVIDA (Processo: AC 0047186085 RS, Relator(a):Túlio de Oliveira Martins, Julgamento: 03/05/2012, Órgão Julgador: Décima Câmara Cível, Publicação: Diário da Justiça do dia 06/07/2012.
} 
O presente estudo tem, pontualmente, o interesse de discutir os requisitos de validade do negócio jurídico envolvendo a relação médico-paciente, não se aventurando por outras disciplinas circunstantes da relação médico-paciente, as quais se conhecem, mas que não serão estudadas por questões de opção acadêmica e metodológica.

O ponto inicial que se pretende incorporar na mente das pessoas é o de que as relações entre médico-paciente estão classificadas como fato jurídico, sendo de interesse do direito o estudo da natureza desses fatos, em face das consequências de seus atos e ações, e em especial, neste caso, no estudo dos requisitos de validade.

Neste sentido, deve-se esclarecer a seguinte indagação: Tratando-se de um tema que envolve o comportamento da pessoa na relação médico-paciente, não deveria o estudo ser realizado por um médico, dentro da prática diária da medicina?

A princípio a resposta seria positiva. É certo que há detalhes e questões de ordem técnica e profissional que envolve a comunicação de uma doença, de um tratamento e de um procedimento invasivo que cabe ao médico ter o controle e saber lidar com as emoções do paciente.

Contudo, as expectativas sociais decorrentes da relação entre médicopaciente são fenômenos normatizados ${ }^{3}$ diante da necessidade da sociedade em estabelecer uma ordem que possa regular o comportamento das pessoas umas com as outras, em seu convívio diário na sociedade (FERRAZ, 1994, p. 103).

Assim, o comportamento ${ }^{4}$ do médico diante do paciente é tipificado por normas que configuram suas responsabilidades, deveres, faculdades e poderes (FERRAZ, 1994, p. 104)

Desta maneira, apesar de caber ao médico o reconhecimento da melhor forma de lidar com o paciente, este comportamento é juridicamente normatizado pela sociedade que aguarda que as ações e reações do médico sigam uma conduta previamente pensada, de modo que se estabeleça uma ordem, um procedimento expectado quanto ao seu comportamento.

\footnotetext{
3 "Na sua finalidade de ordenar a conduta humana, obrigatoriamente, o direito valoriza os fatos e, através das normas jurídicas, erige à categoria de fato jurídico aqueles que têm relevância para o relacionamento inter-humano." (MELLO, 2003, p. 7).

4 "Definimos comportamento como um "estar em situação. Quem está em situação transmite mensagens, quer queira quer não. Comportar-se é estar em situação com os outros, os endereçados das mensagens, os quais também estão em situação. Donde, comportamento é troca de mensagens, comunicação. Essa troca de mensagem é o elemento básico da sociedade, do sistema social." (FERRAZ, 1994, p. 104).
} 
Há assim fatos relevantes na relação médico-paciente, que em face de sua importância nas relações sociais recebem da ordem jurídica um tratamento especial, imputando efeitos jurídicos quanto ao seu resultado. ${ }^{5}$

A relação médico-paciente é um fato social relevante para as pessoas, assim, em razão disto, o Estado edita normas jurídicas com o objetivo de que a conduta prevista seja a mesma adotada por seus destinatários.

A normatização do comportamento humano, da qual não escapa a relação médico-paciente, busca conter o caráter individualista do ser humano, pois, se cada pessoa pudesse agir segundo as suas próprias razões, sem regras que evitassem os conflitos de interesses, as relações na sociedade seriam incontroláveis, por isso que a exigência de normas de conduta para a sociedade de forma obrigatória e incondicional visa garantir o mínimo de ordem nas relações sociais humanas. ${ }^{6} 7$

A atuação do médico é, assim, sujeita a regras próprias que dominam a sua conduta no exercício da arte médica (lege artis medicinae) e na sua relação com o paciente. A relação médico-paciente é um fato jurídico normatizado que além de impor direitos e obrigações determinam efeitos jurídicos a este mesmo comportamento.

\footnotetext{
5 "Em verdade, somente o fato que esteja regulado pela norma jurídica pode ser considerado um fato jurídico, ou seja, um fato gerador de direitos, deveres, pretensões, obrigações ou de qualquer outro efeito jurídico, por mínimo que seja." (MELLO, 2003, p. 9).

6 "O homem (homo sapiens) não é um produto simples da natureza, mas o resultado do convívio com os outros homens. Por isso, apesar de sua sociabilidade, há nele, sempre, algo de próprio, tipicamente individual, que não se dissolve no social nem se torna comum. Assim, não é possível negar que o homem jamais se despe, por completo, de seus instintos egoístas, motivo pelo qual não se consegue apagar, nem mesmo superar, a sua inclinação, muito natural, de fazer prevalecer os seus interesses quando em confronto com os seus semelhantes. Além disso, todo arcabouço social, respaldado no aparato de meios que visam a adaptá-lo, não consegue suprimir ou reduzir o seu livre arbítrio na escolha de como comportar-se. Parece indiscutível, no entanto, que se a cada qual fosse permitido conduzir-se socialmente como bem lhe aprouvesse, deixando-se governar pelo seu egoísmo e ambição, tendo como medida de ação o seu poder e a fraqueza do outro, a vida em comunidade seria intolerável e praticamente impossível o avanço para formas superiores de civilização. Não se poderia, ao menos, considerar sociedade humana um agrupamento dessa ordem. O jugo social representado pela atuação no sentido de adaptação é aceito como uma imposição necessária à vida social. Por isso, traz como resultante ineliminável a possibilidade sempre presente de reação e rebeldia do homem aos padrões traçados pela sociedade. Disso decorre, evidentemente, a imperiosa exigência da comunidade de estabelecer normas de conduta que tenham um caráter obrigatório em decorrência do qual a sua impositividade ao homem seja incondicional e independente da adesão das pessoas. Essas regras constituem as normas jurídicas que, no seu conjunto, consubstanciam o direito da comunidade em que elas são vigentes." (MELLO, 2003, p. 4).

7 "A definição usual de direito reza: direito é o conjunto de normas coativas válidas num Estado, e essa definição ao meu ver atingiu perfeitamente o essencial. O dois fatores de que ela inclui são o da norma e o da realização por meio de coação... O conteúdo da norma é um pensamento, uma proposição (proposição jurídica), mas uma proposição de natureza prática, isto é uma orientação para a ação humana; norma é, portanto, uma regra conforme a qual nos devemos guiar.”(IHERING apud FERRAZ, 1994, p. 101).
} 
Desde Hipócrates, o médico está sujeito às regras de comportamento perante o seu paciente, em que se compromete a ter uma postura de acordo com preceitos pré-estabelecidos para o bem estar do doente.

Hoje, as regras de comportamento do médico estão representadas pelo Código de Ética Médica, Resolução CFM no. 1.931/2009.

A estruturação de normas relativas ao comportamento do médico obriga que a análise da relação médico-paciente não seja simplesmente do ponto de vista da medicina, mas também do ponto de vista do direito e das demais disciplinas envolvidas.

\section{PREVISÃO NORMATIVA DA RELAÇÃO MÉDICO-PACIENTE COMO REGRA DE SOLUÇÃO DE CONFLITOS}

A norma-jurídica que regula a relação médico-paciente se desenvolve no campo da validade, no plano do dever ser, enquanto vontade criada pelo pensamento humano que se dirige a uma conduta que se intenciona obrigatória (MELLO, 2003, p. 10). Ou seja, a comunidade jurídica, levando em consideração os aspectos da relação médico-paciente, edita normas, com o objetivo de que os médicos e os pacientes sigam aquelas determinações quando se verificarem aqueles fatos antes previstos. Assim, a norma jurídica isoladamente é algo abstrato que está dirigido aos fatos concretos da relação médico-paciente, que se vierem a acontecer irão produzir os efeitos determinados pela própria norma. Podendo-se considerar diante da norma que a atitude do médico foi válida ou inválida.

No Brasil, o Código de Ética médica do Conselho Federal de Medicina ${ }^{8}$ regula a relação médico-paciente determinando como deve ser o seu comportamento. As normas jurídicas se apresentam como um modelo de conduta a ser seguido pelos médicos, em face da valoração dos fatos da vida social, com o objetivo de que a relação médico-paciente seja a mais harmônica possível (MELLO, 2003, p. 14).

Por sua vez, pode acontecer que as relações entre médico e paciente sejam dissonantes e não tenham a devida harmonia dentro de um mundo ideal, possibilitando o surgimento de conflitos diante da divergência entre a vontade do médico e a vontade do paciente. Assim, apesar do dever do médico de

${ }^{8}$ De acordo com a Lei 3.268 de 30 de setembro de 1957, que dispõe sobre os Conselhos de Medicina e atribui ao Conselho Federal o poder de votar e alterar o Código de Deontologia médica. 
cuidar da saúde do paciente, sendo o alvo de toda a sua atenção, pode ser que o paciente recuse o tratamento, ou solicite tratamento diverso daquele que entende prescrever o médico.

A regra é a de que o paciente quer ser tratado pelo médico. E que o médico quer tratar o paciente. Mas quando o paciente recusa o tratamento médico, irá ocorrer uma colisão de princípios, entre a autonomia do paciente e o dever de beneficência do médico, de modo a frustrar o médico em seu oficio de cuidar da saúde do paciente. Então se pergunta: é moralmente permitido para um médico tratar o paciente contra a sua vontade? (VAUGHN, 2013, p. 72).

Se por acaso, o paciente for um adulto de posse de todas as suas competências mentais, em condições de manifestar a sua vontade, a recusa ao tratamento apresenta-se como a solução mais adequada ao caso. Assim, a recusa ao tratamento e a não intervenção do médico, pode ser considerada uma atitude válida perante a norma jurídica. Porém, se o paciente for um menor de idade e seus pais recusarem o tratamento por questões de ordem religiosa, a realização do tratamento contra a vontade dos pais, será, neste caso, a solução mais adequada, sendo a recusa ao tratamento uma opção inválida.

Por outro lado, pode ocorrer um fato em que a expectativa que o paciente tem em relação ao seu tratamento médico possa não ser compatível com o procedimento a ser realizado pelo médico, ou seja, o paciente confia que o médico irá realizar determinado procedimento pré-estabelecido diante de uma determinada situação, enquanto que o médico entende que se as condições do paciente forem as mesmas previstas quando do exame clinico será cumprida a sua determinação, caso contrário, realizará o médico o tratamento conforme as suas próprias convicções, diante do novos fatos apresentados (FERRAZ, 1994, p. 107).

Qual seria, nesse caso, a opção válida perante a norma jurídica?

A manutenção da pretensão do paciente perante a palavra dada pelo médico, a qual deve ser cumprida, ou, a modificação da palavra dada em face da alteração das circunstâncias, diante das condições não serem mais as mesmas quando do momento em que a palavra foi dada? ${ }^{9}$

\footnotetext{
9 "À expectativa normativa de A (a palavra dada deve ser cumprida) pode contrapor-se a expectativa normativa de B (a palavra dada deve ser cumprida, desde que as condições em que foi dada sejam as mesmas)." (FERRAZ, 1994, p. 107).
} 
A dinâmica da relação médico-paciente impõe o estudo da norma jurídica e dos conflitos existentes em face da autonomia da vontade do paciente e das circunstâncias que envolvem as relações sociais. ${ }^{10}$

Daí que diante das várias estruturas sociais e das diversas projeções normativas surgem os conflitos e a necessidade de determinar qual o sentido que a norma deverá tomar naquele caso em concreto, perante as diversas circunstâncias que o fato apresente, sendo o direito, na presença de uma ordem pré-estabelecida, o instrumento para a solução desses conflitos.

A dinâmica da relação médico-paciente não foge da apreciação do direito.

Os fatos resultantes das relações médico-paciente deverão ser analisados a partir das normas jurídicas existentes, as quais dirigirão a sociedade para a solução mais adequada para cada caso em concreto, uma vez que a mesmas foram previamente objeto de valoração para tornar a convivência social mais harmônica. ${ }^{11}$

\section{A ANÁlise dOS SUPORTES FÁTICOS QUE DÃO VALI- DADE AO NEGÓCIO JURÍDICO DA RELAÇÃO MÉDICO- PACIENTE}

O negócio jurídico constitui uma declaração de vontade dirigida a produção de efeitos jurídicos determinados pela própria intenção do agente. ${ }^{12}$ Como visto, a lei vai atribuir efeitos jurídicos de acordo com a vontade da pessoa que a manifesta (ASCENSÃO, 1999, p. 22).

Assim, para que a manifestação de vontade receba do ordenamento jurídico o seu pleno reconhecimento e produza efeitos, é necessário que o negócio jurídico preencha alguns requisitos essenciais à verificação de sua validade.

\footnotetext{
10 "Surgem, assim, conflitos das projeções normativas que resultam da superprodução de normas. Estes conflitos não são exceção, mas o comum na vida social. A dogmática tem de se haver como esse problema. O princípio da inegabilidade dos pontos de partida exige a postulação de normas preponderantes que, em caso de conflitos, devem prevalecer. A teoria dogmática do direito pressupõe que estas normas preponderantes são as consideradas jurídicas.” (FERRAZ, 1994, p. 108).

11 "Como procuramos deixar claro, a norma jurídica constitui um modelo de conduta estabelecido pela comunidade jurídica, como resultado da valoração dos fatos da vida, com a finalidade de obter a adaptação do homem à convivência social harmônica." (MELLO, 2003, p. 14).

12 "Os negócios jurídicos são actos jurídicos constituídos por uma ou mais declarações de vontade, dirigidas à realização de certos efeitos práticos, com a intenção de os alcançar sob tutela do direito, determinando o ordenamento jurídico a produção dos efeitos jurídicos conformes à intenção manifestada pelo próprio declarante ou declarantes." (PINTO, 1996, p. 379).
} 
Tais condições, que podemos denominar de suportes fáticos que dão validade ao negócio jurídico são: o sujeito, o objeto e a forma de exteriorização da vontade. $.^{13},{ }^{14}$

Segundo a doutrina de Marcos Bernardes de Mello (2004, p. 21), a primeira categoria, a do sujeito, se refere ao problema da manifestação da vontade, visando resguardar a pessoa em face de sua consciência e autenticidade. A segunda categoria, a do objeto, se refere à consonância do ato jurídico com o direito e com a natureza das coisas. E a terceira categoria, a da forma de exteriorização da vontade, tem por fundamento os pressupostos de certos atos jurídicos que por sua relevância devem ser realizados de acordo com algumas solenidades, visando resguardar e documentar a conclusão e prova do negócio jurídico.

Neste sentido, passaremos a analisar cada um dos elementos que compõem o suporte fático da relação médico-paciente, de acordo com a teoria geral do direito civil.

\section{DO SUJEITO DO NEGÓCIO JURÍDICO DA RELAÇÃO MÉDICO-PACIENTE}

Como no negócio jurídico os seus efeitos são determinados pela vontade do agente, o estudo do sujeito do negócio jurídico visa essencialmente proteger a pessoa e sua manifestação de vontade, por serem estes os seus principais elementos.

A manifestação da vontade se expressa na relação médico-paciente quando em busca do tratamento adequado para sua enfermidade o paciente solicita ao médico a prestação dos seus serviços. Há a formação de um verdadeiro contrato em que o médico assume a obrigação de fornecer os cuidados necessários àquela enfermidade, quando não a própria cura, e o paciente os deveres de colaboração e informação, além do dever de proceder com o pagamento dos encargos que derivem das prestações dos cuidados à saúde.

\footnotetext{
13 "Diz-se válido o ato jurídico cujo suporte fáctico é perfeito, isto é, os seus elementos nucleares não têm qualquer deficiência invalidante, não há falta de qualquer elemento complementar. Validade, no que concerne a ato jurídico, é sinônimo de perfeição, pois significa a sua plena consonância com o ordenamento jurídico." (MELLO, 2004, p. 4)

14 "Art. 104 do Código Civil Brasileiro: A validade do negócio jurídico requer: I- Agente capaz;IIObjeto lícito, possível, determinado ou determinável; III- forma prescrita ou não defesa em lei."
} 
Contudo, nem toda relação médico-paciente pode ser definida como uma relação contratual, mas mesmo assim, não se foge a necessidade de estudo da manifestação da vontade e seus efeitos, principalmente, no negócio jurídico unilateral, em que a vontade isolada do médico intervindo na esfera jurídica do paciente, somente pode ser concebida para o bem do próprio paciente.

Assim, tanto no negócio jurídico bilateral quanto no negócio jurídico unilateral, o estudo da manifestação da vontade é essencial para a caracterização do tipo legal que está a ser praticado e se o mesmo preenche os requisitos necessários para a sua validade.

A vontade manifestada para que produza efeitos jurídicos deve ser consciente, para que não seja considerada nula ou inexistente, por isso, segundo Marcos Benardes de Mello (2003, p. 14), o ordenamento jurídico estabelece critérios para que possa ser entendida como plenamente consciente a vontade.

O primeiro critério adotado pela ordem jurídica é a capacidade para agir, ou seja, a capacidade para o exercício do direito por si mesmo, a qual tem em seu núcleo a análise objetiva da existência dos requisitos determinados por lei para que a pessoa dirija a sua vida na ordem civil, com autonomia.

A capacidade para exercício do direito é uma regra, que tem na própria lei os seus limites, os quais quando ultrapassados resultam na incapacidade da pessoa. (PEREIRA, 2007, p. 270)

Assim, a manifestação plena da vontade depende da existência de uma vontade realmente autônoma, em que a pessoa possua o completo discernimento dos fatos, das circunstâncias e dos efeitos que envolvem o negócio jurídico.

Na relação médico-paciente, como negócio jurídico, o médico deve ter a consciência se o paciente tem, de acordo com a lei, a capacidade para exercer a sua vontade, por si mesmo, de forma autônoma. ${ }^{15}$

A capacidade para o exercício do direito, segundo o Código Civil brasileiro é dividido em graus, levando em consideração se a pessoa possui uma maior ou menor aptidão para atuar autonomamente, realizando negócios jurídicos. Assim, há a classificação da incapacidade em absoluta, quando ocorre a total falta de

\footnotetext{
15 "A capacidade de agir é estado pessoal. Ser capaz é qualificação atribuída pelo direito às pessoas em geral, sendo que, em relação aos seres humanos, nem todos a têm. Diz incapaz aquele a quem as normas negam a capacidade de praticar, pessoalmente, ato jurídico válido. A incapacidade, na verdade, constitui exceção à regra da capacidade. Tem por fundamento a necessidade de proteger as pessoas naturais que, por algum motivo relacionado à vivência nas relações negociais, à sanidade física ou mental, à situação cultural ou à impossibilidade física de administrar seus bens e praticar os atos respectivos são consideradas sem experiência de vida e sem as condições de discernimento que lhes permitam ter a plena consciência das consequências práticas de seus atos." (MELLO, 2003, p. $25)$.
} 
capacidade para a prática dos atos da vida civil, e a incapacidade relativa, quando a pessoa não é capaz para a prática de certos atos, ou a forma de exercê-los (MELLO, 2003, p. 26).

O Código Civil brasileiro utilizou critérios baseados na idade, na saúde mental e na falta de discernimento da pessoa para determinar a sua incapacidade. Contudo, a análise da capacidade a partir da idade não gera grandes conflitos ou controvérsias, em face da simples contagem do tempo, em que, a princípio, há a certeza legal da capacidade e do discernimento, se outras causas mentais não existirem como limitadoras da capacidade desta mesma pessoa. Tal critério é utilizado pelo legislador de forma arbitrária, com a compreensão de que a partir de certa idade a pessoa passa a ser capaz, o que torna as relações jurídicas mais seguras, pois, objetivamente não haveria dúvidas quanto à capacidade no momento da realização do negócio jurídico. ${ }^{16}$

Por sua vez, a análise dos elementos que determinam a limitação da capacidade em face da saúde mental e da falta de discernimento requer uma investigação mais profunda, a qual deve ser objeto de prova, em especial com o pronunciamento de um médico, que poderá determinar o grau de insanidade. ${ }^{17} 18$

Um exemplo típico relativo à análise da capacidade de discernimento de uma pessoa está no seguinte caso julgado por um Tribunal Inglês: Mr. Park, uma pessoa idosa que havia sofrido previamente um mal súbito severo, casou com sua segunda esposa em uma determinada manhã e no mesmo dia à tarde ele realizou o seu testamento. Ele morreu depois de um breve tempo e sua família desafiou judicialmente a validade do casamento e a viúva contestou a validade do testamento. Ele foi declarado mentalmente capaz para se casar,

\footnotetext{
16 "Não pode, porém, ficar ao sabor das influências individuais a cessação da incapacidade absoluta decorrente da idade. $\mathrm{O}$ direito quer a proteção dos menores, mas quer também a estabilidade das relações sociais. Por isso, atendendo ao momento da transição da ausência de participação na vida jurídica, para a convocação do menor a dela tomar contato e nela ter ação, não pode deixar à apreciação de cada caso a aferição do grau de aptidão e de discernimento, sob pena de instituir grave insegurança nos negócios. Se assim procedesse nunca se saberia, com exatidão, se o menor, como agente em um negócio jurídico, havia ou não eficazmente manifestado a sua vontade.” (PEREIRA, 2007, p. 275).

${ }^{17}$ Não se descarta a prova testemunhal para determinar a falta de discernimento, além da prova pericial.

18 "As deficiências podem ser mais ou menos profundas: alcançar a totalidade do discernimento; ou , ao revés, mais superficiais: aproximar o seu portador da plena normalidade psíquica. O direito observa estas diferenças e em razão delas gradua a extensão da incapacidade, considerando, de um lado, aqueles que se mostram inaptos para o exercício dos direitos, seja em consequência de um distúrbio da mente, seja em razão da total inexperiência, seja em função da impossibilidade material de participar no comércio civil; de outro lado, os que são mais adequados à vida civil, portadores de um déficit menos pronunciado, ou já mais esclarecidos por uma experiência relativamente ponderável.” (PEREIRA, 2007, p. 272).
} 
mas carecedor da necessária capacidade mental para fazer um testamento. $\mathrm{O}$ seu pouco discernimento e força de raciocínio mantiveram-se suficientes para compreender o que implicava um casamento, mas suas confusões e perdas de memória o desabilitaram em ter a necessária recordação de suas propriedades e de suas obrigações para poder fazer um testamento (BRAZIER; CAVE, 2011, p.145).

Ora, a falta de discernimento pode ser mais ou menos profunda, e ter uma graduação e extensão própria, que se permita dizer que uma pessoa é apta para praticar certos atos da vida civil e outros não. No caso a pessoa pode ser apta para se casar e inapta para dispor dos seus bens.

Evidentemente que a capacidade para o exercício de direitos é posta no Código Civil com um caráter patrimonialista e negocial, contudo diante da necessidade de estudo da relação médico-paciente, veremos que o conceito de capacidade para consentir em um determinado tratamento médico, é bem mais complexo do que uma analise da capacidade em face de uma decisão negocial. ${ }^{19}$

Mas o ponto de partida será sempre as regras de capacidade da Teoria Geral do Direito Civil.

O segundo critério adotado pela ordem jurídica diz respeito à perfeição da vontade manifestada, a sua compatibilidade com a realidade ou a veracidade, consciente de seu conteúdo (MELLO, 2003, p. 22).

Este segundo critério busca avaliar se a vontade da pessoa não está viciada por algum fator externo que influencie na autenticidade de sua declaração, fazendo com que manifeste uma vontade que não seria verdadeiramente a sua vontade, se tivesse a exata noção da realidade dos fatos ou se as circunstâncias fossem diferentes (MELLO, 2003, p. 22).

No caso, surgem como elementos necessários para a correta manifestação de vontade as obrigações acessórias como a boa fé e a equidade, de modo que o paciente deve estar devidamente informado de suas condições de saúde, para poder fazer uma decisão mais próxima da realidade dos fatos (MELLO, 2003, p. 22).

Em especial para a perfeita manifestação de vontade é necessário que haja uma compensação em face do desequilíbrio de conhecimento entre o paciente e o médico, de modo que ao prestar as informações necessárias ao paciente, o mesmo tenha condições de visualizar o seu problema de saúde mais

19 "Na verdade, a legislação tradicional referente à capacidade visa proteger mais a propriedade do que as pessoas, portanto, não servem para a capacidade de tomar decisões médicas." (PEREIRA, 2004, p. 148). 
próximo da realidade, fazendo a sua escolha de forma consciente quanto ao seu conteúdo.

Assim, a assimetria de informações, diante da especialidade médica, obriga que o paciente seja informado dos problemas que atingem a sua saúde, de todas as formas de tratamento, os riscos e as convicções pessoais do médico para que então possa manifestar a sua vontade.

A busca deste equilíbrio entre o médico e o paciente não é algo fácil de estabelecer, por isso que o estudo do consentimento informado é tão merecedor de destacada atenção.

A perfeição da vontade manifestada constitui elemento complementar da validade do negócio jurídico (MELLO, 2003, p. 38), daí que a capacidade para manifestar a vontade diante de um tratamento médico não é a mesma para a realização de uma compra e venda de um bem de consumo. A pessoa tem que ter uma capacidade especial, qual seja, a de compreender todas as circunstâncias de ordem médica, todos os efeitos e consequências da doença, seus diversos tratamentos e os riscos a elas inerentes, para poder fazer então uma decisão ausente de qualquer vício invalidante (PEREIRA, 2004, p. 149).

A capacidade do paciente está ligada tanto à sua capacidade de fato dentro da Teoria Geral do Direito Civil ${ }^{20}$, como faculdade que tem a pessoa de por si só tomar as decisões necessários em sua vida, como sujeito de direitos e obrigações, quanto e ainda mais, está ligada verdadeiramente a sua capacidade para tomar decisões acerca das intervenções médicas.

Assim, a capacidade para consentir nos casos que envolvem a relação médico-paciente passa a ser um conceito autonomizado em face da capacidade negocial, uma vez que o objeto da declaração de vontade tem por fundamento um bem diferente daqueles do direito patrimonial, quais sejam, a vida, a saúde, a integridade física e o livre desenvolvimento da personalidade (PEREIRA, 2004, p. 148).

Neste sentido, as condições pessoais do paciente irão influenciar no modo que estas informações serão prestadas, bem como na capacidade do paciente decidir.

Podem ocorrer casos em que a pessoa possa ser considerada capaz para os atos da vida civil, mas que não tenha capacidade para expressar a sua vontade, diante de questões médicas, ou porque se encontra diante de uma dor

20 "A esta aptidão oriunda da personalidade, para adquirir os direitos na vida civil, dá-se o nome de capacidade de direito, e se distingue da capacidade de fato, que é a aptidão para utilizá-los e exercêlos por si mesmo." (PEREIRA, 2007, p. 263). 
insuportável, ou possua um medo relevante que o impeça momentaneamente de expressar a sua vontade. ${ }^{21}$

A analise desta capacidade é realizada pelo próprio médico.

Aquelas pessoas consideradas incapazes serão substituídas por um procurador de cuidados de saúde ou por um ente familiar próximo. Os quais devem ser devidamente informados quanto aos tratamentos que devem ser praticados, seus riscos e benefícios.

Mas aqui há um detalhe importante: a manifestação de vontade do procurador deve ser sempre no sentido de prover o melhor para o paciente, e na medida do possível deve tentar se adequar a vontade do paciente declarada no momento em que possuía capacidade. ${ }^{22}$

Assim, a análise da capacidade do paciente para decidir quanto ao melhor tratamento irá depender da análise do médico, caso a caso, o que envolve pacientes com capacidade, pacientes sem capacidade, podendo ainda verificar dentre aqueles quem não possuem capacidade alguns que realizaram manifestação de vontade adiantada, e outros que não se conhece a sua vontade por nunca terem se manifestado.

Além do mais, quanto maior o risco do tratamento médico, maiores devem ser os cuidados com o respeito aos direitos do paciente, principalmente quanto à análise de sua capacidade para decidir. ${ }^{23}$

\footnotetext{
21 "Por vezes é preciso levar em conta, na aferição da competência, que a vulnerabilidade do paciente, a angústia provocada pelo diagnóstico confirmador de certas patologias, dificulta assertivas categóricas, incontestáveis, quanto à racionalidade e, portanto, quanto à competência. Porém, inequívoco que algum critério de avaliação que permita apurar, com certo grau de confiabilidade ou segurança, se a pessoa sabe o que pode ocorrer, caso decida de forma equivocada, deve ser desenhado." (SZTAJN, 2012, p. 184).

22 "Segundo este critério toma-se a decisão que está de acordo com os melhores interesses do paciente (best interests of the patient), o que se indentifica, naturalmente, com a proposta terapêutica do médico. Assim, a aplicação deste standard poderia ser vista como uma ratificação da proposta do médico. Este critério pretende-se objetivo, no sentido de que não se centra nos valores e na personalidade do paciente, mas na sua condição física e no prognóstico traçado, sendo certo que a neutralidade valorativa é meta inalcançável. Hoje em dia, entende-se que nos interesses do paciente devem estar envolvidos não apenas os interesses médicos, mas também o respeito pelos seus valores e pelas suas presumíveis vontades, pelo que, de algum modo, se desenha um "critério sincrético' que combina os dois últimos referidos." (PEREIRA, 2004, p. 239).

23 "Lo mismo sucede con la capacidad de razonamiento y deliberación. Pero con respecto a ambas cosas vale la idea indudable de que no existe un estándar general de competencia, de forma que pudiéramos decir que dado ciertos rasgos de una persona podemos ya declarar en términos generales si es o no es competente, sino que, muy por el contrario, el grado de competencia de cada uno depende, no sólo de quien es cada uno, sino también de los problemas que tiene ante sí, y en nuestro caso, depende de los problemas de salud sobre los que debe adoptar una decisión. No es lo mismo decidir sobre una cura trivial o un episodio leve de enfermedad conocida(la gripe común, por ejemplo) que decidir sobre una intervención de riesgo." (SAN MIGUEL, 2010, p. 30).
} 
A capacidade decisória é assim, a habilidade para entender os riscos, benefícios e alternativas e para realizar uma decisão razoável.

Mas para que a capacidade decisória seja exercida de forma livre e plena, é necessário que a divulgação da informação seja suficientemente esclarecida.

Assim, a capacidade como requisito de validade do negócio jurídico em face da relação médico-paciente adquire uma nova exigência como elemento essencial da manifestação da vontade, que tem por objeto a tomada de decisões a respeito dos cuidados de saúde, é no caso, a análise da capacidade para consentir ou recusar um tratamento médico (PEREIRA, 2004, p. 153)

\section{DO OBJETO NA RELAÇÃO MÉDICO-PACIENTE}

Diante da concepção fenomenológica da relação médico-paciente que visa à intervenção do médico na esfera da personalidade do paciente, em seu corpo, sua saúde, sua integridade física e mental, o tratamento médico de sua saúde, ou até mesmo a cura de uma doença, é o objeto da relação jurídica médico-paciente.

Ou seja, na relação médico-paciente, o médico assume uma obrigação de prestar um serviço médico que tem a pretensão de prevenir, diagnosticar, curar, tratar ou diminuir o sofrimento, lesão, perturbação física ou mental. ${ }^{24},{ }^{25}$

Neste sentido, o objeto da relação médico-paciente será a prestação de serviços médicos, que constituem o agir em benefício da saúde do paciente, em todas as suas formas.

A ideia de objeto do negócio jurídico é então a atribuição especifica que as normas jurídicas lhe imputam, sendo no caso da relação médica, a obrigação específica de prover a saúde. Por sua vez, estando o objeto vinculado à determinação da norma jurídica, a qual lhe dará efeitos legais, é necessário que este mesmo objeto para poder ter validade seja lícito, possível e determinável (MELLO, 2003, p. 39).

\footnotetext{
24 "Por outro lado, existe o que se pode chamar de ato médico específico como sendo a utilização estratégica e recursos para prevenir a doença, recuperar e manter a saúde do ser humano ou da coletividade, inseridos nas normas técnicas (lex artis) dos conhecimentos adquiridos nos cursos regulares de medicina e aceitos pelos órgãos competentes, estando quem o executa, supervisiona ou solicita profissional e legalmente habilitado." (FRANÇA, 2013, p. 52).

25 "O alvo de toda a atenção do médico é a saúde do ser humano, em benefício da qual deverá agir com o máximo de zelo e o melhor de sua capacidade profissional." Inciso II, do Código de Ética Médica, Resolução CFM no. 1.931/2009.
} 
Assim, é essencial que a intervenção médica no paciente seja licita, para que o seu objeto seja válido.

Deste modo, a lei que regula a profissão de médico, lei 3.268/57, e o Código de Ética Médica dão o caráter de licitude à intervenção do médico e as práticas dos atos necessários ao bem estar do paciente.

O Código Penal Português, por sua vez, atribui liceidade ao ato médico, impondo alguns requisitos necessários para a sua legalidade, quais sejam: que o agente seja médico, que a finalidade seja terapêutica, com a intenção de prevenir, diagnosticar, debelar ou minorar doença, sofrimento, lesão ou fadiga corporal ou perturbação mental e que a intervenção seja realizada por indicação médica, com o respeito a leges artis. ${ }^{26}$

Nessa linha de pensamento, de acordo com o Código Penal Português são ilícitas as intervenções médicas que não estejam em conformidade com a norma legal. Assim, a necessidade de que o objeto do negócio jurídico seja licito, em face do tratamento médico, o qual deve estar de acordo com a ordem jurídica, determina que as intervenções que um médico realize com o objetivo de praticar o aborto em uma pessoa, bem como a prática da eutanásia, não poderão ser consideradas lícitas, por serem ações contrárias à lei, tornando o negócio jurídico nulo. No mesmo sentido, se a conduta do médico for contrária a leges artis, poderá ser considerada ilícita, inclusive possibilitando ao lesado a busca de uma reparação civil.

Desta forma, a conformidade com o direito determina que o exercício da profissão de médico e a intervenção realizada pelo médico sejam autorizadas pela lei e pela leges artis.

A possibilidade do objeto, também como requisito de validade da intervenção médica, diz respeito não só a possibilidade legal, mas em especial a sua possibilidade física, quando o objeto for materialmente suscetível de se realizar. Nestes casos, a análise da possibilidade material irá depender do estado atual da medicina e dos recursos existentes no momento da intervenção médica.

\footnotetext{
${ }^{26}$ Artigo $150 .^{\circ}$ Código Penal Português- Intervenções e tratamentos médico-cirúrgicos

1 - As intervenções e os tratamentos que, segundo o estado dos conhecimentos e da experiência da medicina, se mostrarem indicados e forem levados a cabo, de acordo com as leges artis, por um médico ou por outra pessoa legalmente autorizada, com intenção de prevenir, diagnosticar, debelar ou minorar doença, sofrimento, lesão ou fadiga corporal, ou perturbação mental, não se consideram ofensa à integridade física.

2 - As pessoas indicadas no número anterior que, em vista das finalidades nele apontadas, realizarem intervenções ou tratamentos violando as leges artis e criarem, desse modo, um perigo para a vida ou perigo de grave ofensa para o corpo ou para a saúde são punidas com pena de prisão até dois anos ou com pena de multa até 240 dias, se pena mais grave lhes não couber por força de outra disposição legal.
} 
Neste sentido, não seria possível materialmente que o médico propusesse a um paciente do sexo masculino que o mesmo engravidasse, com a gestação de uma criança por 9(nove) meses. Atualmente, é impossível materialmente que um homem possa dar a luz a uma criança, sendo por isso nulo o contrato médico que tenha por objeto um tratamento específico para este fim. Da mesma forma, pode-se dizer em relação a um tratamento que propusesse um transplante de cérebro que pelo atual estado da medicina é impossível.

A impossibilidade pode ser absoluta ou relativa. Será absoluta quando a prestação médica for impossível de ser realizada por qualquer pessoa, como é o caso do transplante de cérebro. Mas será relativa, quando a prestação possa ser realizável por outra pessoa, como é o caso da gravidez que é permitida materialmente às mulheres e não é para os homens. Dependendo da forma que a impossibilidade relativa se apresenta, ela não será causa de nulidade do negócio jurídico.

Por fim, a determinação do objeto diz respeito à individualização e certeza quanto ao tipo de prestação a ser realizada, ou ao menos a possibilidade de determinação posterior da prestação, em face da algum critério eleito pelas partes. Em caso de um tratamento médico de fecundação assistida, a determinação do objeto é a própria fecundação, através de suas várias etapas. Contudo, em alguns casos não é possível especificar o objeto do tratamento médico, em face da ausência de um diagnóstico exato, não sendo possível conhecer antecipadamente de forma individualizada o tipo de tratamento ou intervenção que será realizada, o qual poderá depender de diversos fatores que envolvem também as condições de saúde do paciente, sendo o tratamento determinado de uma forma geral, como a obrigação do médico de tratar o paciente e atuar para o bem de sua saúde, sem especificar de forma antecipada qual será o tratamento.

A determinação do objeto irá variar conforme a natureza do tratamento e a especialidade do médico. Sendo, por sua vez, a atividade médica uma atividade de meios, mesmo que o médico não tenha sucesso na intervenção desejada e não consiga êxito quanto à pretensão determinada pelo tratamento, a relação não será considerada nula.

Assim, para a validade do negócio jurídico envolvendo médico e paciente, o tratamento médico que será realizado deverá ser lícito, possível e determinado ou determinável. 


\section{DA FORMA DE MANIFESTAR A VONTADE NA RELAÇÃO MÉDICO-PACIENTE}

A vontade da pessoa, como elemento essencial do desenvolvimento de sua personalidade, é uma construção que se processa em três momentos. Um momento interior de recebimento dos impulsos externos; outro momento interior de ponderação e resolução de como irá proceder; e um terceiro momento em que leva para o exterior a sua vontade deliberada (PEREIRA, 2007, p. 481).

A manifestação dessa vontade deliberada pode ser realizada de variadas formas. ${ }^{27}$

Como requisito de validade do negócio jurídico pode a lei exigir que a manifestação da vontade obedeça a certas regras para que possa produzir efeitos jurídicos. Assim, a forma, em um determinado momento pode tomar um sentido de expressão da manifestação da vontade, como modo de exteriorizar a vontade e em outro momento, pode ter o sentido de requisitos e regras que a lei impõe para que um determinado negócio jurídico tenha existência e eficácia (PEREIRA, 2007, p. 488).

Em regra o direito brasileiro admite a liberdade das formas, mas para alguns atos jurídicos a lei impõe como requisito essencial para a sua existência que a manifestação da vontade seja declarada através de uma forma especial. Quando esta forma especial for exigida, o negócio somente terá existência e validade em caso de cumprimento da forma.

Em geral, na relação médico paciente não há uma exigência de forma, apesar da necessidade do médico realizar as devidas anotações nos prontuários e na ficha do paciente. Contudo, a manifestação da vontade, tem como regra geral a liberdade de forma.

Deste modo, não é exigido ao médico que solicite do paciente a sua manifestação de vontade escrita, salvo quando a própria lei o exigir como requisito de validade, contudo, até mesmo um gesto pode representar o consentimento do paciente para a realização do tratamento, quando no momento for o único meio existente para declarar a vontade. ${ }^{28}$

\footnotetext{
27 "A forma do negócio jurídico é o meio técnico, que o direito institui, para a externação da vontade. É a projeção ambiental da elaboração volitiva, a expressão exterior do querer do agente. A primeira vista, parece que não cabe ao direito civil cogitar do exame da forma. Se se atentar, porém, em que não existe ato jurídico sem exteriorização, essa matéria assume o aspecto de correlação profunda com a essência do negócio jurídico." (PEREIRA, 2007, p. 487).

28 "A validade da declaração negocial não depende da observância de forma especial, salvo quando a lei o exigir. É essa, naturalmente, também a regra na relação médico-paciente, onde deve predominar a oralidade." (PEREIRA, 2004, p. 456).
} 
Em alguns casos, conforme a norma jurídica venha determinar, a forma é requisito obrigatório, e isto se verifica, por exemplo, nos casos de inseminação artificial. Nos casos de reprodução humana assistida o Conselho Federal de Medicina exige que o consentimento informado para ser válido deva ser realizado na forma escrita, através de formulário próprio, com a concordância por escrito das pessoas submetidas às técnicas de reprodução assistida. ${ }^{29}$

A liberdade das formas, como regra geral, não impede que uma forma mais solene seja utilizada pelo médico para obter o consentimento informado do paciente, bem como para ajustar o objeto próprio da relação jurídica. ${ }^{30}$

A forma é elemento importante para a relação jurídica, pois, além de ser o meio de exteriorizar a vontade é o modo de fazer prova da existência do negócio jurídico. Quanto mais ariscado o procedimento médico, mais deve o médico se preocupar em resguardar a validade do negócio jurídico solicitando do paciente ou dos seus representantes leais a sua manifestação de vontade na forma escrita.

\section{CONSIDERAÇÕES FINAIS}

A vontade é o núcleo essencial do negócio jurídico, pois, a partir da manifestação da vontade surgirão os efeitos jurídicos pretendidos pela pessoa. Assim, o conteúdo do negócio jurídico é constituído pela estipulação determinada pelas partes ou pela pessoa unilateralmente, de acordo com sua autonomia privada. ${ }^{31}$

Segundo Caio Mario da Silva Pereira (2007,p. 480) há no negócio jurídico a convergência da atuação da vontade e do ordenamento jurídico, ou seja, a vontade é orientada no sentido de produzir efeitos jurídicos.

\footnotetext{
29 "3 - O consentimento informado será obrigatório a todos os pacientes submetidos às técnicas de reprodução assistida, inclusive aos doadores. Os aspectos médicos envolvendo as circunstâncias da aplicação de uma técnica de RA serão detalhadamente expostos, assim como os resultados obtidos naquela unidade de tratamento com a técnica proposta. As informações devem também atingir dados de caráter biológico, jurídico, ético e econômico. O documento de consentimento informado será expresso em formulário especial e estará completo com a concordância, por escrito, das pessoas submetidas às técnicas de reprodução assistida." Inciso I, número 3, da Resolução do CFM $\mathrm{n}^{\mathrm{o}} 1.957 / 2010$.

30 "Dentro do princípio da liberdade de forma, admite-se que a vontade se manifeste por todos os meios, seja pela linguagem falada ou escrita, seja pela linguagem mímica, gestos, acenos, atitudes, seja ainda pela utilização de caracteres convencionais gráficos. Sempre que não for exigida forma especial, o negócio perfaz-se através de um meio qualquer, por que se apure a emissão volitiva. Um gesto é uma forma de manifestação de vontade." (PEREIRA, 2007, P. 490)

31 "O conteúdo do negócio jurídico é a regulação que nele é posta em vigor, no âmbito da autonomia privada." (VASCONCELOS, 2005, p. 417).
} 
A compreensão da vontade do paciente é importante para a validade do tratamento médico. As várias circunstâncias que envolvem o tratamento médico podem influenciar na construção da vontade do paciente, tendo relevância e influência as informações que receba do médico e os seus valores existenciais para que o mesmo possa formar a sua convicção.

O estudo da vontade é bastante importante para a eficácia da declaração na relação médico-paciente. Uma vez que, a construção da vontade dentro da perspectiva psíquica, a qual impõe uma deliberação ${ }^{32} \mathrm{de}$ acordo com as informações que venha a receber do médico e as circunstâncias que envolvem o tratamento, dependerá para a sua validade e eficácia de que a manifestação exteriorizada esteja em consonância com o intimo querer da pessoa, e que não se traduza, em face das circunstâncias, em uma falsa noção da realidade.

Assim, o paciente para manifestar a sua vontade recebe, desde logo, os estímulos provocados pelos sintomas do mal que lhe atinge, as aflições, as dores, os sofrimentos, os quais integram as circunstâncias em que a sua vontade é expressa.

Em seguida, ainda diante dos estímulos exteriores, o paciente recebe do médico as informações necessárias para compreender os sintomas e o mal que lhe atinge, bem como a forma ou formas de tratamento daquela doença, e o prognóstico de sucesso e cura.

Diante desses estímulos exteriores, do qual tem relevância as informações prestadas pelo médico, as circunstâncias do tratamento, as dores, o sofrimento, a cultura e os valores que a pessoa possua, o paciente fará sua deliberação, ponderando o que imagina ser melhor para si naquele momento, para ao final elaborar a sua vontade.

Elaborada a vontade, surge o terceiro momento, em que esta mesma vontade é manifestada para o exterior, sendo reconhecida pelo médico.

Ora, se o paciente tiver a exata noção da realidade dos fatos, estando devidamente informado, sendo capaz, e que as dores não tenham viciado a sua vontade, estando a sua vontade manifestada em sintonia com a vontade interior, não estaremos diante de nenhum problema de ordem jurídica quanto à validade e eficácia da manifestação de vontade.

\footnotetext{
32 "No campo puramente psíquico distinguem-se três momentos: o da solicitação, o da deliberação e o da ação. Primeiramente os centros cerebrais recebem o estimulo do meio exterior; em seguida, mais ou menos rapidamente, ponderam nas conveniências e resolvem como proceder; e finalmente reage a vontade à solicitação." (PEREIRA, 2007, p. 481).
} 
Contudo, caso o paciente não tenha recebido as informações necessárias, e que as dores e o sofrimento tenham influenciado em sua capacidade para decidir, não the permitindo ter a exata noção da realidade, a manifestação de vontade exteriorizada por esta pessoa não será válida, nem eficaz.

Daí a importância do estudo do instituto do negócio jurídico e seus requisitos de validade.

Para a validade da manifestação da vontade, adotando-se a teoria objetivista a partir da impressão do destinatário, deve-se acrescentar ao sentido declarado pelo paciente, todas as circunstâncias que envolvem o seu tratamento, as dores, sofrimentos e emoções, como forma de auxiliar a correta compreensão de sua vontade, e como elemento essencial para a busca do seu desejo interior.

Deste modo, a busca pela vontade interior depende das circunstâncias que determinaram a manifestação da vontade do paciente para a realização do tratamento, onde passa a ter importância os seus valores e a sua cultura, o seu estado de hipossuficiente em relação ao médico, entre outras circunstâncias possíveis, para se tentar chegar a uma vontade mais próxima de sua realidade interna, e o respeito a esta vontade.

É evidente que a estrutura do negócio jurídico na relação médicopaciente difere da estrutura de uma relação obrigacional patrimonialista, haja vista que o objeto especifico da obrigação envolve interesses da personalidade como o corpo, a saúde e a vida do paciente, valores estes que superam os bens patrimoniais, determinando uma função social especifica para os contratos de saúde, com regras própria para a relação médico-paciente.

Assim, a valoração da vontade do paciente integra uma lógica de respeito ao desenvolvimento de sua autonomia pessoal, seu corpo, sua saúde, sua vida, valores estes fundados no principio da dignidade da pessoa humana, que alteram a função do negócio jurídico médico em relação ao negócio jurídico patrimonial.

Desta forma, a busca pela vontade interior do paciente deve ser uma obstinação do médico, pois, as suas expectativas em relação ao seu bem estar, envolve, entre outros aspectos, os seus valores, sua cultura, os seus sentimentos, de modo que o respeito a vontade do paciente interessa a garantia do livre desenvolvimento da personalidade deste mesmo paciente.

O estudo da relação médico-paciente não foge de sua adequação aos requisitos de validade do negócio jurídico, agente capaz, objeto licito, forma prevista em lei e consentimento válido. 


\section{REFERÊNCIAS}

ANDRADE, Manuel A. Domingues. Teoria geral da relação jurídica. Coimbra: Livraria Almedina, 1974. v. 2: Facto jurídico, em especial negócio jurídico.

ASCENSÃO, José de Oliveira. Direito civil: teoria geral. Coimbra: Coimbra Editora, 1999.

BRAZIER, Margaret; CAVE, Emma, Medicine. Patients and the law. London: Peguin Books, 2011.

CONSELHO FEDERAL DE MEDICINA. Resolução CFM Nº 1931/2009. Aprova o Código de Ética Médica. Diário Oficial da União, Brasília, de 24 de setembro de 2009, Seção I, p. 90.

FERRAZ JUNIOR, Tercio Sampaio. Introdução ao estudo do direito. 2. ed. São Paulo: Atlas, 1994.

FRANÇA, Genival Veloso. Direito médico. Rio de Janeiro: Forense, 2013.

MELLO, Marcos Bernardes de. Teoria do fato jurídico: plano da validade. São Paulo: Saraiva, 2004.

Saraiva, 2003.

. Teoria do fato jurídico: plano de existência. 12. ed. São Paulo:

PEREIRA, André Gonçalo Dias. O consentimento informado na relação médico-paciente. Coimbra: Coimbra Editora, 2004.

PEREIRA, Caio Mario da Silva. Instituições de direito civil. 22. ed. Rio de Janeiro: Forense, 2007. v. I.

PINTO, Carlos Alberto da Mota. Teoria geral do direito civil. Coimbra: Coimbra Editora, 1996.

SAN MIGUEL, Francisco J. Laporta. Algunas incógnitas del principio de autonomia personal en tratamientos médicos. In: BUERGO, Blanca Mendoza 
(Coord.). Autonomia personal y decisiones médicas: cuestione éticas y jurídicas. Plamplona: Thomson Reuters, 2010. p. 19-34.

SZTAJN, Rachel. Reflexões sobre o consentimento informado. In:

AZEVEDO, Alvaro Vilaça, LIGIERA, Wilson Ricardo (Org.). Direitos do paciente. São Paulo: Saraíva, 2012. v. 1, p. 173-190.

VASCONCELOS, Pedro Paes de. Teoria geral do direito civil. 3. ed. Coimbra: Almedina, 2005.

Submetido em: 02/10/2014 Aprovado em: 10/03/2015

Como citar: BELTRÃO, Silvio Romero. A adequação da relação médicopaciente aos requisitos de validade do negócio jurídico: a relação médicopaciente como fenômeno jurídico. Scientia Iuris, Londrina, v.19, n.1, p.83104, jun.2015. 